\section{Comentários}

\author{
Csaba Deák*
}

\title{
Sôbre os Alcances e Efeitos da Realimentação Social Tipo Lógico
}

Referimo-nos à realimentação social em geral e à realimentação social tipo lógico, como definidas por $\mathrm{N}$. Wiener em Cibernética e sociedade. 1 Colocada a realimentação social como condição de aprendizado do organismo constituído pela sociedade, 0 referido autor coloca a realimentação "tipo lógico", como uma realimentaçã̃o de nível mais alto, não de ações, mas de condutas. ${ }^{2}$

Sentimos, com Wiener, a importância daqueles processos de informação social, como influindo, senão determinando diretamente o tipo de organização social. Em outros têrmos, a estrutura social é determinada pelo processo de comunicação social. ${ }^{3} \mathrm{O}$ processo de comunicação unidirecional leva a estrutura social hierárquica (rígida do ponto de vista estrutural) e o processo de comunicação bidirecional (realimentação), através de aprendizado, à estrutura social democrática, ou socialista (aberta, do ponto de vista estrutural), segundo a nomenclatura preferida. ${ }^{4}$ Podemos fàcilmente constatar que, na realidade, em tôdas as sociedades existentes, coexistem os dois tipos de processos de comunicação, resultando em sociedades nem perfeitamente rígidas, fechadas, nem perfeitamente abertas, livres. ${ }^{5}$

Podemos também discernir, embora com menos facilidade - hipótese que admitiremos no que segue - que a tendência da civilização chamada ocidental (que podemos admitir como a única sobrevivente na Terra) seja, atualmente, o aumento da proporção

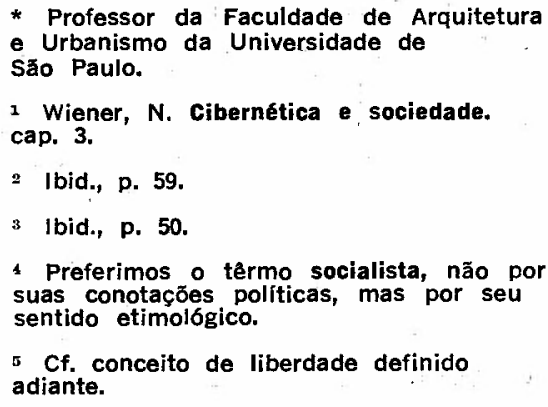

5 Cf. conceito de liberdade definido adiante. 
da comunicação bidirecional em detrimento da

unidimensional. ${ }^{6}$

Descrevemos, até aqui, apenas um processo de cunho evolucionista que se encaixa perfeitamente na visão do mundo com entropia crescente e com bolsões (áreas da vida) de sistemas com entropia decrescente, ${ }^{7}$ dos quais a civilização humana seria um.

Queremos agora focalizar, em apenas alguns parágrafos, um conceito que parece ser desenvolvimentista, ou perfeccionista, emitido através do exemplo da técnica telefônica. 8 o exemplo sugere que embora os comutadores telefônicos automáticos possam parecer quase perfeitos, na realidade, ainda "esbanjam muito equipamento".

o sistema tem uma capacidade ociosa enorme em relação a cada usuário, pelo fato de permitir a mesma, e só a mesma, facilidade de ligaçăo a qualquer outro usuário, quando, na prática, a enorme maioria do número de ligações de cada usuário é efetuada a um número reduzido de outros, cujo conjunto varia pouco em função do tempo. Portanto, o sistema poderia ser aperfeiçoado, aumentando-se seu rendimento com a instalação de um dispositivo de realimentação que registraria as ligaçōes havidas de cada usuário e proporcionaria uma crescente facilidade de ligações (tempo de espera, custo) com o número de ligações havidas.

Parece-nos que o aperfeiçoamento sugerido por Wiener, além do indubitável aumento do rendimento do sistema, produziria um efeito secundário considerado indesejável pelo próprio Wiener, a saber, o aumento de rigidez do sistema. ${ }^{\circ}$ Parece que a aludida inovação induziria um processo de fechamento do sistema de comunicações. Com efeito, a facilidade de se comunicar com aquêles com quem já se comunicou compeliria cada usuário - além dos motivos que são alheios ao sistema em questão - a comunicar-se com aquêles usuários com quem já se comunicou, de modo que êsses usuários formariam um grupo que tenderia a ser fechado, uma vez que a compulsão (originada na relativa facilidade de comunicação) tenderia a aumentar com o tempo. Portanto, se não levarmos em conta outras condições, a tendência dêsse sistema de comunicações realimentado no sentido de aumentar sua economicidade, levaria à formação de grupos sociais fechados.

Pode parecer pessoal ou subjetivo a preferência, ou não, de multiplicar contatos com indivíduos conhecidos ou estabelecer contatos com indivíduos desconhecidos, mas do ponto de vista social haverá consenso em reconhecer que a sociedade resultante do sistema de comunicaçōes acima descrito, apesar de não ser uma sociedade de castas, talvez nem mesmo de classes, teria uma tendência inerente de fechamento, tendência essa que é contrária àquela observada nas sociedades pós-industriais contemporâneas.

As consideraçōes acima dizem respeito apenas a opiniōes sôbre a desejabilidade ou não dos efeitos de uma realimentação informada por um fim específico, ${ }^{10}$ no caso do exemplo citado de Wiener, o aumento da economicidade do serviço telefônico.

Uma consideração seguinte nos coloca, porém, uma dúvida quanto à coerência interna do pensamento exposto na obra citada, pelo menos em alguns de seus pormenores.

As passagens já referidas segue a afirmação ${ }^{11}$ de que a realimentação é o processo pelo qual é facultado ao organismo (máquina, homem, sociedade) ir contra a tendência entrópica de que o mais provável sobrepuja o menos provável. Por outro lado, se examinarmos os efeitos da realimentação do sistema referido, constataremos que a realimentação em questão induz um processo entrópico, uma vez que uma chamada telefônica entre pessoas conhecidas é mais provável que entre pessoas desconhecidas. Esse processo pode ser verificado ainda na sociedade resultante de grupos fechados, isto é, em grupos fechados ou entre pessoas conhecidas há diminuição de informação: ${ }^{12}$ Concluímos, pois, que há uma contradição entre as afirmações do exemplo do sistema telefônico realimentado e a passagem acima aludida.

Estamos inclinados a acreditar que se trata, no caso do sistema de comunicações telefônicas, de um processo de saturação, nos têrmos em que é referido na nota 6 .

Queremos dizer com isso que, indubitàvelmente, 0 aparecimento das comunicações telefônicas constitui um passo no sentido negentrópico: de fato, a telefonia possibilita comunicações afastadas geogràficamente,

\footnotetext{
- Sem querer situar o processo atual em seu contexto histórico. Se fóssemos considerar a evoluçăo dessa tendência na história conhecida, provàvelmente haveria consenso no reconhecimento de ciclos, cada um com a tendéncia acima descrita, sucedendo-se num processo de saturaçőes das estruturas correspondentes a cada ciclo, a conseqüente mudança de estrutura de um ciclo para o seguinte.

$\checkmark$ Op. cit., cap. 2.

- Ibid., p. 59.

- Cf. nota 3.

10 Portanto, bastaria substituir o fim especifico por outro, para provàvelmente chegarmos a efeitos desejáveis.

21 Ibid., p. 61.

1e Ficamos sujeitos a observação que por outro lado, entre pessoas desconhecidas, năo pode haver informaçăo, por excesso de ruído.
} 
até então altamente improváveis. No enfoque considerado, o invento da telefonia é o início de um ciclo negentrópico, em relação ao ciclo anterior. ${ }^{13}$ Provàvelmente, o ciclo em si atinge, com o tempo, uma fase de saturação, como assinalado na figura 1 .

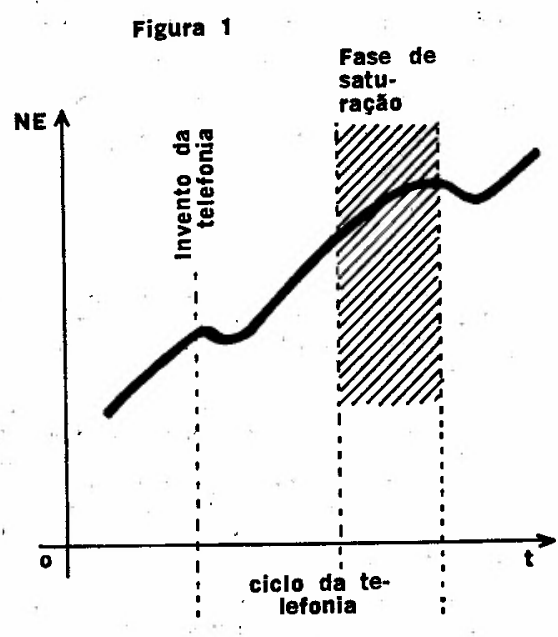

Não temos condições de afirmar que o sistema telefônico esteja, no presente momento, em sua fase de saturaçăo. Isto depende de condições técnicas: podem advir aperfeiçoamentos que dêem continuidade por algum tempo ao processo negentrópico dentro do ciclo. ${ }^{14}$ Mas o que decorre das considerações que fizemos nos parágrafos anteriores, é que se o único aperfeiçoamento capaz de aumentar o rendimento do sistema telefônico é aquêle sugerido por Wiener, então o sistema telefônico entrou em fase de saturação. E é provável a iminência de nova invenção para iniciar nôvo ciclo no sistema de comunicações, que suceda ao ciclo maturado.

Voltando à realimentação social, podemos tirar algumas conclusões a partir da análise do exemplo do sistema de comunicações.

Admitiremos inicialmente que um processo de realimentação é informado por uma

finalidade - 15 no caso do sistema telefônico, a maior rentabilidade - de modo que tôdas as mudanças de condicionamento externo são avaliadas em função de um fim específico e as atitudes do organismo são corrigidas em função de aumentar as probabilidades para o organismo atingir aquêle fim.

No caso do organismo constituído pela sociedade, existem vários fins simultâneos e de graus e áreas de atuação diversos, cada um informando um processo de realimentação que capacita a sociedade a atingir aquêles fins, o que não significa que todos os processos de realimentação ajam no sentido negentrópico: isso dependerá da natureza do fim a ser atingido, conforme vimos no caso do exemplo discutido acima.

Essa contradição e aparente absurdo são superados pela regressão final. Com efeito, podemos considerar todos os fins específicos como intermediários, ordenados em função de um fim não discutível. 0 conceito acêrca dêsse último fím tem variado através da história de nossa civilização, sendo que hoje a estrutura de nosso pensamento indica a própria vida como o fim indiscutível. Em têrmos denotativos, a vida é característica dos organismos que contrariam a segunda lei da termodinâmica. Portanto, em têrmos denotativos, o fim irredutível dos organismos vivos, ${ }^{16}$ e como tal da sociedade, é a diminuição da entropia.

Em função dêsse fim irredutível, fins intermediários que visam à ação e informam processos de realimentação são fixados.

Ocorre que êsses fins têm alcances diversos no tempo e no campo das açōes. Existem fins imediatos como ir ao Rio de Janeiro, por exemplo. Esse fim determina uma série de ações necessárias, controladas por um processo de realimentação informado pelo fim em questão. Seja, por exemplo, a série de ações programadas: "fazer as malas, reservar hotel no Rio, lubrificar o carro"; ao surgir um nôvo fato como: "meu amigo vai ao Rio na mesma época, eu posso ir com êle e seu carro é mais veloz", o processo

de realimentação, tendo em vista o fim "ir ao Rio", alterará o programa de ações e vai substituir "Iubrificar o carro" por "combinar com o amigo a hora e local da partida". No enfoque considerado, êsse processo de realimentação é do tipo lógico e é análogo àquele discutido no exemplo do sistema telefônico.

Mas existem também fins mais remotos como (para relacionar com o exemplo anterior) de "resolver um assunto numa repartição que funciona no Rio", que desencadeou uma série de programas de ação com fins intermediários, dos quais um é aquêle "ir ao Rio" 17 do exemplo anterior.

A possível obsolescência de um processo - e do fim específico correspondente - fica clara ao imaginarmos o seguinte: durante o funcionamento dos processos que visam aos fins intermediários, "ir ao Rio", por exemplo, surge uma nova condição no meio: recebemos a informação de que "a dita repartição transferiu-se para Brasília".

0 processo de realimentação informado pelo fim "resolver um assunto na dita repartição" alterará parte dos fins

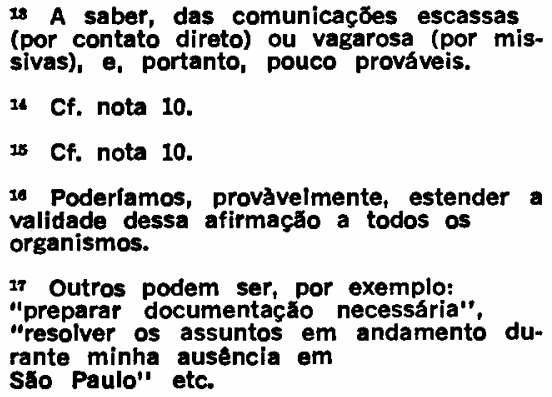


intermediários e vai substituir "ir ao Rio" por "ir a Brasília", tornando obsoleto, por ser entrópico, o fim "ir ao Rio" e o processo de realimentação correspondente. ${ }^{18} \mathrm{Se}$ o eu do exemplo fôr uma organização complexa, a substituição do fim intermediário "ir ao Rio" por "ir a Brasília" levará certo tempo e o processo "ir ao Rio", já obsoleto, continuará a funcionar durante algum tempo.

Quanto mais complexo fôr o organismo ou sistema, tanto mais difíceis serão as mudanças corretivas em função de novas condições, pois maior será o número de subsistemas em funcionamento, que deverão ser realimentados. E o caso da sociedade, e essa é a razão pela qual no organismo social extremamente complexo coexistem processos entrópicos e negentrópicos. 19

Cabem aqui duas considerações: 1. A coexistência de processos entrópicos e negentrópicos na sociedade não só não é contraditória, ainda menos absurda, mas é inerente ao próprio sistema pelo fato de não existirem comunicações instantâneas: o sistema "ir ao Rio", do nosso exemplo, funciona até ser substituído por "ir a Brasília". O que se pode fazer é reduzir as áreas entrópicas pela aceleração dos veículos de

informação, o que aliás é, sem dúvida, uma tendência da sociedade. 2. É difícil, na prática, discernir quais subsistemas pertencem a sistemas entrópicos, pelo fato de que nem todos os subsistemas de um sistema entrópico são forçosamente entrópicos em si. Isto se torna claro se analisarmos o que ocorre no exemplo acima no momento em que o sistema "resolver um assunto numa repartição que funciona no Rio" é realimentado. 0 subsistema "ir ao Rio", entrópico, é substituído por "ir a Brasília". A nova programação será: "fazer as malas", "reservar hotel em Brasília" e "lubrificar o carro". Vemos que apenas um item, "reservar hotel no Rio", do sistema obsoleto, é alterado, conservando-se os outros dois. ${ }^{20}$

Em sistemas extremamente complexos, como a sociedade, onde há superposição de número não-infinito, porém não-inumerável de sistemas, a dificuldade de discernimento dos processos entrópicos aumenta excessivamente e escapa ao processamento digital. 21

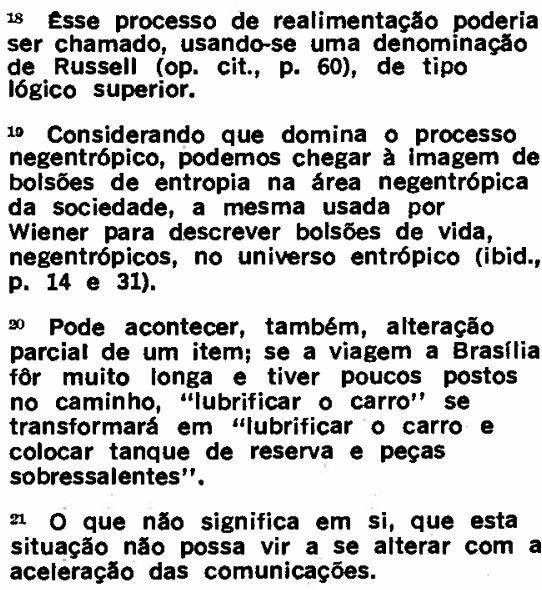

A Comissāo Econômica para a América Latina - CEPAL edita publicaçōes sôbre desenvolvimento econômico, agricultura, comércio, indústria, etc., além das seguintes revistas:

Boletín Económico de América Latina

Boletín Estatístico de América Latina

Estudio Económico de América Latina

Para melhores informaçōes, escreva à

FUNDAÇÃO GETÚLIO VARGAS,

Serviço de Publicaçōes, Praia de Bołafogo 188 ,

Caixa Postal 21.120, ZC-05, Rio de Janeiro, GB.
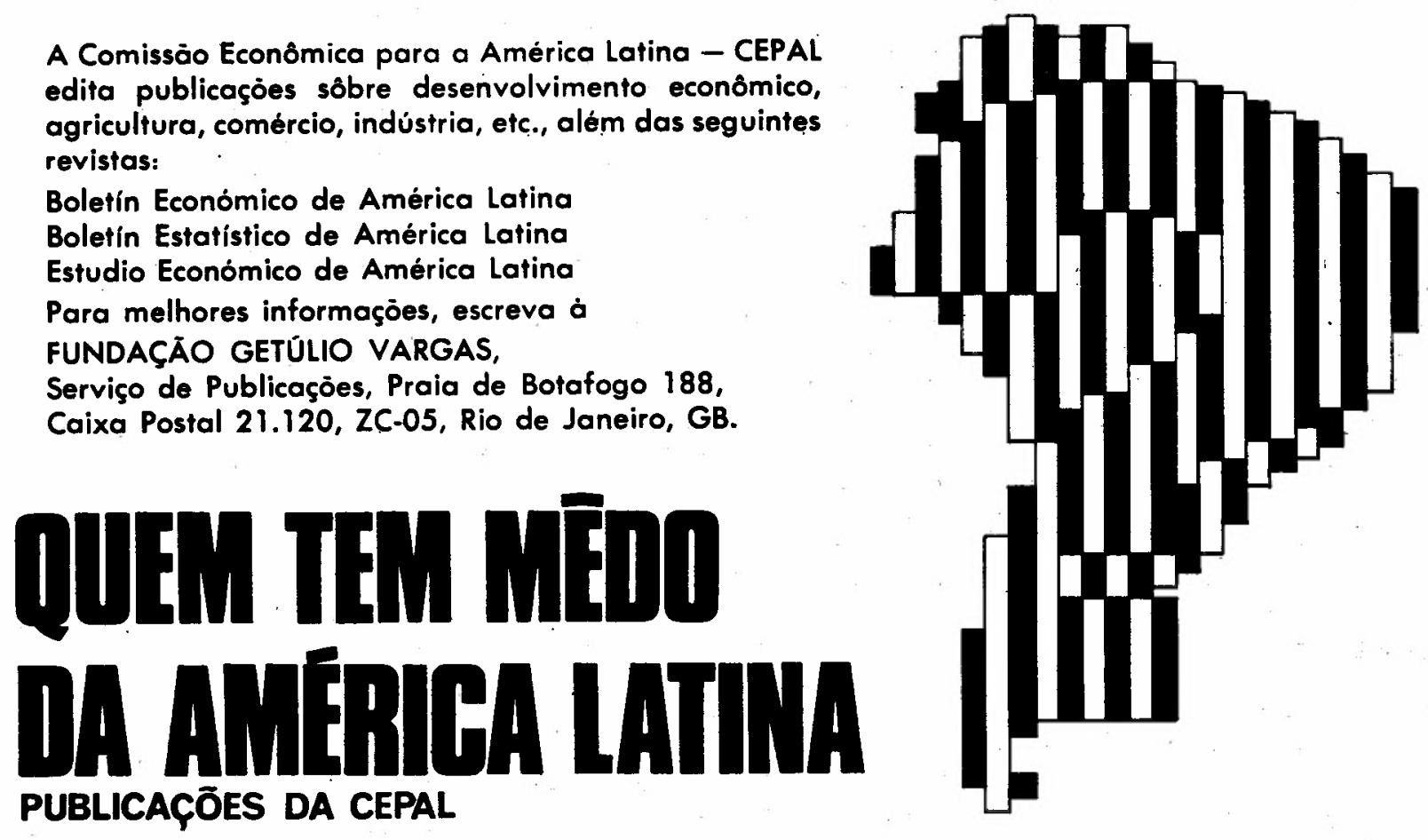